\title{
Carnes, Aves, Pescado, Frijoles/Guisantes Secos, Huevos y Nueces $^{1}$
}

Glenda L. Warren ${ }^{2}$

\section{El grupo de las Carnes y los Granos}

Escoja 2-3 porciones todos los días. Escoja carnes bajas en grasa, aves sin la piel, pescado y frijoles o guisantes secos a menudo.

\section{¿Qué es una porción?}

- 2 a 3 onzas de carne baja en grasa cocida, aves o pescado.

- $\quad 1 / 2$ taza de frijoles secos cocidos ó 1 huevo cuenta como una onza de carne baja en grasa.

- 2 cdas de mantequilla de cacahuate (maní) ó $1 / 3$ taza de nueces cuenta como una onza de carne.

El obtener suficientes alimentos de de este grupo no representa un problema para mucha gente. Solo se necesitan de 2 a 3 servicios diarios, un total de 7 onzas de carne baja en grasa cocida es suficiente para obtener la proteína que se necesita.

Las carnes, aves y el pescado suplen proteína, vitamina $B$, hierro y zinc. Los otros alimentos en este grupo - frijoles secos, huevos y nueces - son similares a las carnes porque también proveen proteína y muchas vitaminas y minerales. $\mathrm{La}$ Pirámide de los Alimentos sugiere de 2 a 3 servicios cada día de los alimentos que se encuentran en este grupo. La cantidad total de estos servicios debe de ser equivalente a 5 ó 7 onzas de carne cocida baja en grasa, aves o pescado por día.

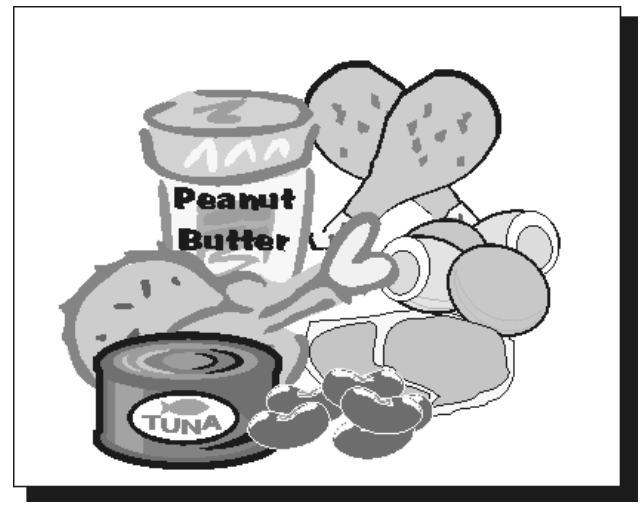

\section{Como preparar las Carnes de modo que le disminuya el contenido de grasa:}

- Corte toda la grasa que sea posible. Corte los pedazos de grasa que tenga la carne, el pollo el pavo antes de cocinarla. Remueva la piel de las aves antes de cocinarlas.

1. This document is FCS1058-Span, one of a series of the Department of Family, Youth and Community Sciences, Florida Cooperative Extension Service, Institute of Food and Agricultural Sciences, University of Florida. Publication date: April 2003. First published: September 1997. Reviewed by: Jennifer Hillan MSH, RD, LD/N, Family, Youth \& Community Sciences, University of Florida, Gainesville, FL 32611. Please visit the EDIS Web site at http://edis.ifas.ufl.edu

2. Glenda L. Warren, M.S., R.D., CFCS, associate professor, Extension Nutritionist-EFNEP, Department of Family, Youth and Community Sciences, Cooperative Extension Service, Institute of Food and Agricultural Sciences, University of Florida, Gainesville, 32611. 
- Ase, hornee o hierva estos alimentos en lugar de freirlos.

- Si usted decide freír estos alimentos ocasionalmente, trate de tosatarlos en un horno en lugar de freirlos sumergidos en aceite. (Humedezca las aves con agua o leche. Cúbralas con galleta molida, pan molido o maíz molido. Pongalas a cocinar en el horno.)

- Sustituya la carne molida de res por carne molida de pavo o pollo cuando prepare platos a base de carne molida, como espagueti o pastelón

- Enfríe los guisos y las sopas antes de servirlas de modo que pueda remover la grasa que se acumula en el tope.

- Limite el consumo do las salsas que son altas en grasa saturada, como la salsa de crema.

- Modifique las recetas de modo que use cantidades más pequeñas de carnes bajas en grasa y más cantidades de ingredientes como papas, arroz, granos y vegetales.

Algunos alimentos caen en más de un grupo de alimentos. Los frijoles/guisantes secos y lentejas pueden contar como un servicio ya sea en el grupo de las carnes y los granos o en el grupo de los vegetales. Este tipo de alimento puede contar como un servicio en cualquiera de los grupos pero

\section{Mantenga el Contenido de Sodio Bajo}

- Use polve de ajo o de cebolla en lugar de condimentos con sal.

- Condimente usando hierbas y especias.

- Use las salsas preparadas comercialmente de forma esporádica, usualmente son altas en azúcar, sodio o ambos.

\section{Ocho Consejitos para Seleccionar y Servir Carnes, Aves, Pescado, Frijoles/Guisantes Secos, Huevos y Nueces}

- Escoja carnes bajas en grasa, aves sin piel, pescado y frijoles o guisantes secos a menudo. Estos son las opciones más bajas en grasa.

- Compre pescado fresco o congelado ( $\sin$ sabor añadido); también puede comprar tuna enlatada y empacada en agua.

- Sirva más frijoles con las carnes. Muchos frijoles y productos hechos a base de frijoles son casi totalmente libre de grasa y son una buena fuente de fibra y proteína.

- Cuidado con la yerna de los huevos, son altos en colesterol. Cuando prepare platos a base de huevos use un huevo por persona. Prepare porciones más grandes añadiendo claras de huevo adicionales. Una yema de huevo contiene cerca de $215 \mathrm{mg}$ de colesterol. Las clara del huevo no contiene nada de colesterol y se puede usar libremente.

- Las nueces y las semillas son altas en grasa, de modo que consúmalas con moderación.

- Limite el consumo de carnes procesadas altas en grasa como las salchichas, el salami y otros cotes fríos. Seleccione variedades bajas en grasa leyendo la etiqueta que contiene la información nutricional del producto.

- Limite el consumo de órganos cuando vaya a ingerir carnes ( 3 onzas de hígado de pollo cocido contiene cerca de $540 \mathrm{mg}$ de colesterol.)

- Prepare las carnes de modo que le reduzca su contenido de grasa. 


\section{Reduzca el consumo de grasas, grasas saturadas y colesterol}

Siga las recomendaciones que se ilustran en la Pirámide de los Alimentos, las mismas aplican a dietas que se consumen en un termino de varios días y no a comidas o alimentos sencillos que se han de consumir una sola vez.

- Use grasas y aceites de forma esporádica.

- Use la información Nutricional de la etiqueta para que se ayude a seleccionar alimentos bajos en grasa y colesterol.

- Consuma plenitud de productos hechos a base de granos, vegetales y frutas.

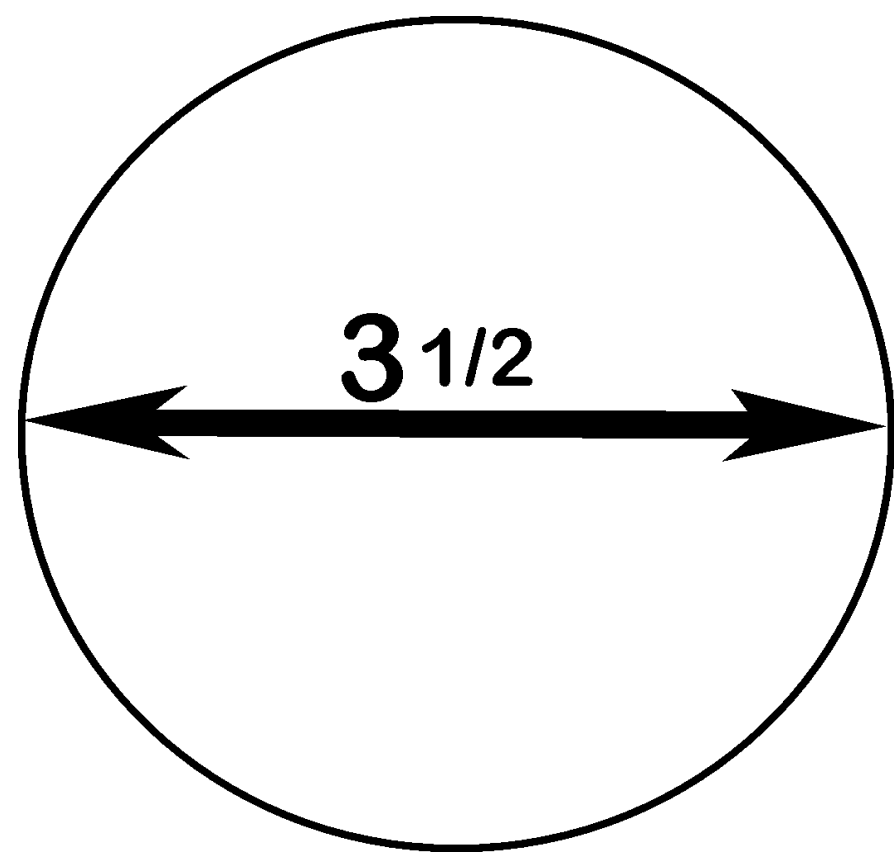

Carne de Hamburguesa

Tamaño Regular (85\% libre de grasa, asada)

Un pedazo de este tamaño: 204 calorías
- Seleccione productos lácteos bajos en grasa, pescado, aves, frijoles o guisantes secos para que obtenga de ellos los nutrientes esenciales sin que aumente sustancialmente las calorías y el consumo de grasas saturadas.

\section{¿Cómo sé lo que es una porción?}

- Tres onzas de carne cocida baja en grasa o de pollo sin la piel son como del tamaño de un paquete de naipes o como del tamaño de la palma de la mano de una mujer. Estas tres onzas proveen alrededor de 6 gramos de grasa.

- Tres onzas de carne a la que no se le ha cortado la grasa o de pollo con piel contienen el doble de grasa que la carne baja en grasa o que el pollo sin piel.

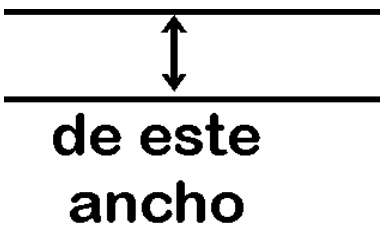




\section{Escoja alimentos de cada uno de los 5 grupos de alimentos}

La Pirámide de los Alimentos nos muestra la importancia de mantener un balance entre los alimentos que comemos a diario. La mayoría de los alimentos que seleccionamos a diario deben ser de los grupos de alimentos más grandes y que están cerca a la base de la pirámide.

- Escoja la mayoría de sus alimentos del grupo de los productos de granos (6-11 porciones), del grupo de los vegetales (3-5 porciones) y del grupo de las frutas (2-4 porciones).
- Consuma en cantidades moderadas alimentos del grupo de la leche (2-3 porciones) y del grupo de las carnes y frijoles (2-3 porciones).

- Use limitadamente alimentos que tienen pocos nutrientes pero mucha grasa y azúcar.

Nota: El número de porciones para cada grupo de alimentos están en intérvalos. El número menor es para aquellas personas quienes consumen 1600 calorías al día como las mujeres sedentarias. El número mayor es para quienes consumen alrededor de 2800 calorías al día como los hombres activos.

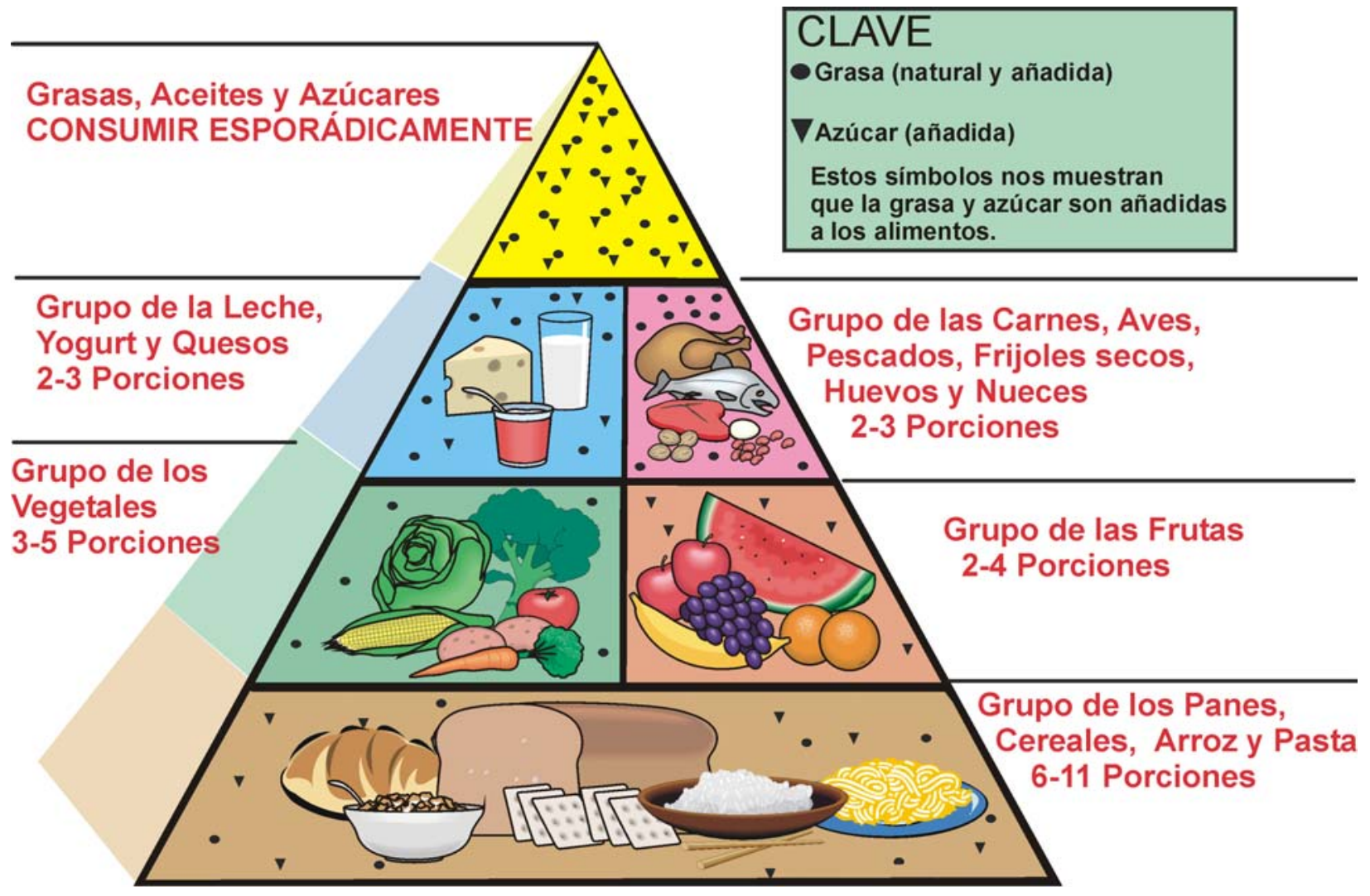

This publication is supported with funding from the Expanded Food and Nutrition Education Program, USDA's Food Stamp Program, Florida Department of Children and Families, and University of Florida Cooperative Extension Service, in collaboration with state, county, and local agencies. The Food Stamp Program gives nutrition assistance to people with low income. It can help you buy nutritious foods for a better diet. To find out more, call 1-800-342-9274 (toll-free). 